\title{
ANALISIS KANDUNGAN ZAT PEWARNA Rhodamin B PADA SAUS JAJANAN DAN TINGKAT PENGETAHUAN PEDAGANG DI SEKOLAH DASAR NEGERI \\ (Studi Kasus di Kecamatan Taman Kabupaten Sidoarjo Tahun 2015)
}

Aprillina Yunita, Mamik, Sukiran Al Jauhari

\begin{abstract}
ABSTRAK
Rhodamin $B$ merupakan zat warna tambahan yang dilarang penggunaannya dalam produkpangan. Tujuan penelitian mengetahui kandungan Rhodamin $B$ secara kualitatif saus jajanan yang di jual di sekolah dasar serta untuk mengetahui besar tingkat pengetahuan pedagang tentang penggunaan zat pewarna sintetik yang dilarang penggunaannya.
\end{abstract}

Penelitian ini bersifat "Deskriptif" menggambarkan ada tidaknya kandungan Rhodamin B pada saus yang dijual di Sekolah Dasar Negeri. Populasi dan sampel dalam penelitian ini yaitu semua merk saus yang dijual pedagang jajanan di Sekolah Dasar Negeri dan pedagang tetap yang ada di 31 Sekolah Dasar Negeri. Analisa data dilakukan secara deskriptif yaitu pemeriksaan organoleptik, pemeriksaan kimia, serta tingkat pengetahuan pedagang saus .

Hasil pemeriksaan fisik saus bahwa 2 dari 3 sampel tidak menampakkan ciri yang mengandung Rhodamin $B$ sedangkan 1 sampel menampakkan ciri yang mengandung Rhodamin $B$. Penilaian tingkat pengetahuan pedagang jajanan bahwa 3 pedagang memiliki pengetahuan "Kurang"dan 28 pedagang memiliki pengetahuan "Cukup".

Sebagian besar saus menunjukkan ciri penggunaan Rhodamin $B$ dan produsen yang positif menggunakan saus mengandung Rhodamin B mempunyai pengetahuan "Cukup". Masyarakat sebagai pembeli harus teliti dalam membeli jajanan yang menggunakan saus, dan harus teliti dalam mengetahui ciri-ciri saus yang mengandung Rhodamin $B$.

Kata Kunci : Rhodamin B,tingkat pengetahuan pedagang

\section{PENDAHULUAN}

Makanan merupakan suatu hal yang sangat penting didalam kehidupan manusia. Makanan yang kita makan bukan saja harus memenuhi gizi dan mempunyai bentuk yang menarik, akan tetapi juga harus aman dalam arti tidak mengandung mikroorganisme dan bahan-bahan kimia yang dapat menyebabkan penyakit (anwar $d k k, 1989$ ).

Menurut Peraturan Menteri Kesehatan Republik Indonesia Nomor: 239/MENKES/PER/V/1985, Rhodamin B merupakan zat warna tambahan yang dilarang penggunaannya dalam produkproduk pangan. Rhodamin B dapat menyebabkan iritasi saluran pernafasan, iritasi kulit, iritasi pada mata, iritasi pada saluran pencernaan, keracunan, dan gangguan hati dan bahkan kanker hati, akan tetapi sampai sekarang masih banyak produsen yang menggunakan Rhodamin B dalam produk makanan dan minuman yang dihasilkannya. Ciri-cirimakanan yang mengandung Rhodamin B antara lain makanan berwarna merahmencolok dan cenderung berpendar serta banyak memberikan titik-titik warna karenatidak homogen, baunya tidak alami sesuai makanannya (Trestiati, 2003).

\section{Tujuan}

1. Mengidentifikasi ciri fisik saus yang mengandung Rhodamin $B$ yang di jual di Sekolah Dasar Negeri wilayah Kecamatan Taman Kabupaten Sidoarjo

2. Menganalisis ada tidaknya kandungan Rhodamin $B$ pada saus jajanan yang di jual di Sekolah Dasar Negeri wilayah Kecamatan Taman Kabupaten Sidoarjo

3. Menilai tingkat pengetahuan penjual saus jajanan di Sekolah Dasar Negeri wilayah Kecamatan Taman Kabupaten Sidoarjo.

\section{METODE PENELITIAN}

\section{Jenis Penelitian}

Jenis penelitian ini adalah penelitian bersifat deskriptif dimana dalam penelitian ini dilakukan untuk membuat gambaran tentang objek penelitian. Gambaran tersebut mengenai kandungan zat pewarna Rhodamin B pada saus jajanan dan tingkat pengetahuan pedagang di Sekolah Dasar Negeri wilayah Kecamatan Taman Kabupaten Sidoarjo tahun 2015. 


\section{Populasi dan Sampel}

1. Objek penelitian adalah semua merk saus tomat yang dijual pedagang pada jajanan pada Sekolah Dasar Negeri wilayah Kecamatan Taman, Kabupaten Sidoarjo.

2. Sampel untuk menilai tingkat pengetahuan adalah semua pedagang tetap yang ada di 31 Sekolah Dasar Negeri dari 45 Sekolah Dasar Negeri. Dengan rumus :

$$
\begin{aligned}
n & =\frac{N}{1+N\left(d^{2}\right)} \\
n & =\frac{45}{1+45(0.01)} \\
& =31 \text { Sampel Sekolah Dasar Negeri }
\end{aligned}
$$

\section{Teknik Pengambilan Sampel}

Teknik pengambilan sampel pada penelitian ini menggunakan teknik Judgment Sampling, dimana peneliti menentukan kriteria-kriteria yang dijadikan dasar pada pengambilan sampel .

\section{Hasil Penelitian dan Pembahasan}

Kecamatan Taman berada di wilayah utara dari Kabupaten Sidoarjo, berjarak kurang lebih $20 \mathrm{Km}$ dari Ibukota Kabupaten. Di Kecamatn Taman terdapat suatu daerah yang dikenal dengan nama Sepanjang. Sepanjang bisa disebut sebagai ibu kota kecamatan Taman.

\section{A. Hasil Pemeriksaan Secara Fisik Kandungan Rhodamin $B$ Pada Saus Jajanan Yang Di Jual Di Sekolah Dasar Negeri Wilayah Kecamatan Taman Kabupaten Sidoarjo}

Pemeriksaan secara fisik kandungan Rhodamin $B$ pada saus jajanan yang di jual di Sekolah Dasar Negeri Wilayah Kecamatan Taman Kabupaten Sidoarjo dilakukan berdasarkan ciri-ciri kandungan Rhodamin $B$ di dalamnya, yakni: warnanya cerah mengkilap dan lebih mencolok, terkadang warna terlihat tidak homogen (rata), ada gumpalan warna pada produk, bila dikonsumsi rasanya sedikit lebih pahit, baunya tidak alami sesuai makanannya. Secara Rinci dapat diuraikan pada tabel 1 berikut ini:

Tabel 1

Hasil Pemeriksaan Secara Fisik Kandungan Rhodamin B Pada Saus Jajanan Yang Di Jual Di Sekolah Dasar Negeri Wilayah Kecamatan Taman Kabupaten Sidoarjo Tahun 2015

\begin{tabular}{|c|c|c|c|c|}
\hline $\begin{array}{c}\text { Kode } \\
\text { sampel }\end{array}$ & $\begin{array}{l}\text { Warnanya cerah } \\
\text { mengkilap dan lebih } \\
\text { mencolok }\end{array}$ & $\begin{array}{l}\text { Terkadang warna } \\
\text { terlihat tidak homogen } \\
\text { (rata), ada gumpalan } \\
\text { warna pada produk }\end{array}$ & $\begin{array}{l}\text { Bila dikonsumsi } \\
\text { rasanya sedikit } \\
\text { lebih pahit }\end{array}$ & $\begin{array}{l}\text { Baunya tidak } \\
\text { alami sesuai } \\
\text { makanannya }\end{array}$ \\
\hline
\end{tabular}

Hasil Pemeriksaan secara Fisik berdasarkan kandungan Rhodamin B pada Saus Jajanan

\begin{tabular}{ccccc}
\hline A1 & Negatif & Negatif & Negatif & Negatif \\
\hline A2 & Negatif & Negatif & Negatif & Negatif \\
\hline A3 & Positif & Negatif & Negatif & Positif \\
\hline \multicolumn{2}{c}{ Sumber : Data Primer 2015 } & & &
\end{tabular}

Berdasarkan Tabel 1 diatas dapat dilihat bahwa pada saus dengan kode sampel A1 dan $A 2$ yang seluruhnya tidak menunjukkan 4 kriteria penilaian secara fisik seperti warna tidak cerah mengkilap, warna terlihat homogen (rata), tidak ada gumpalan pada produk, bila dikonsumsi rasanya tidak pahit, serta baunya alami sesuai makanannya. Sedangkan kondisi ini tidak dijumpai pada saus dengan kode A3 yang masih menunjukkan 2 dari 4 kriteria penilaian secara fisik yaitu warna cerah mengkilap dan lebih mencolok, serta baunya tidak alami sesuai makanannya, dan pada 2 kriteria penilaian secara fisik lainnya menunjukkan hasil yang negatif yaitu warna terlihat tidak homogen (rata), ada gumpalan warna pada produk dan bila dikonsumsi rasanya sedikit pahit. 
B. Hasil Pemeriksaan Laboratorium Tentang Kandungan Rhodamin $B$ Pada Saus Jajanan Yang Di Jual Di Sekolah Dasar Negeri Wilayah Kecamatan Taman Kabupaten Sidoarjo

Pemeriksaan Laboratorium Kandungan Rhodamin B Pada Saus Jajanan Yang Di Jual Di Sekolah Dasar Negeri Wilayah Kecamatan Taman Kabupaten Sidoarjo Tahun 2015
Hasil pemeriksaan laboratorium terhadap kandungan Rhodamin $B$ pada saus menggunakan uji Test Kit Colorimetri dapat ditunjukkan pada tabel 2 berikut.

\begin{tabular}{ccc}
\hline No. & Kode Sampel & Hasil Pemeriksaan Rhodamin B \\
\hline 1 & A1 & Negatif \\
\hline 2 & A2 & Pegatif \\
\hline 3 & A3 &
\end{tabular}

Berdasarkan tabel 2 di atas dapat diketahui bahwa 2 sampel saus tidak mengandung Rhodamin $B$, sedangkan 1 sampel saus positif mengandung Rhodamin $B$.
C. Hasil
Tingkat
Pengetahuan
PedagangSaus Jajanan Di Sekolah
Dasar Negeri Wilayah Kecamatan Taman Kabupaten Sidoarjo
Berdasarkan hasil wawancara terhadap 31 pedagang saus jajanan tentang pengetahuan pedagang dalam mengerti dan memahami

tentang Rhodamin $B$ pada saus, diperoleh hasil penilaian berdasarkan jawaban yang diberikan oleh pedagang yang terdiri dari 10 pertanyaan mempunyai nilai sebagai berikut:

a. Bila jawaban yang dipilih "Benar" maka diberi nilai 5

b. Bila jawaban yang dipilih "Cukup" maka diberi nilai 3

c. Bila jawaban yang dipilih "kurang" maka diberi nilai 1

Tabel3

Pengetahuan Pedagang Saus Jajanan Tentang Kandungan Rhodamin B Pada Saus Yang Di Jual Di Sekolah Dasar Negeri Wilayah Kecamatan Taman Kabupaten Sidoarjo Tahun 2015

\begin{tabular}{|c|c|c|c|c|c|c|c|}
\hline \multirow{3}{*}{ No } & \multirow{3}{*}{ Pengetahuan Tentang } & \multicolumn{6}{|c|}{ Hasil } \\
\hline & & \multicolumn{2}{|c|}{$B(5)$} & \multicolumn{2}{|c|}{ C (3) } & \multicolumn{2}{|c|}{$\mathrm{K}(1)$} \\
\hline & & $\mathrm{N}$ & $\%$ & $\mathrm{~N}$ & $\%$ & $\mathrm{~N}$ & $\%$ \\
\hline 1 & Pengertian zat pewarna pada makanan & 19 & 61,29 & 10 & 32,25 & 2 & 6,45 \\
\hline 2 & $\begin{array}{l}\text { Tujuan penambahan zat pewarna pada } \\
\text { makanan }\end{array}$ & 15 & 48,38 & 8 & 25,8 & 8 & 25,8 \\
\hline 3 & Ciri pewarna buatan untuk makanan & 10 & 32,25 & 5 & 16,12 & 16 & 51,61 \\
\hline 4 & $\begin{array}{l}\text { Cara pemilihan zat pewarna yang tepat } \\
\text { untuk makanan }\end{array}$ & 2 & 6,45 & 14 & 45,16 & 15 & 48,38 \\
\hline 5 & Pengertian Rhodamin & 0 & 0 & 14 & 45,16 & 17 & 54,83 \\
\hline 6 & $\begin{array}{l}\text { Alasan pedagang menggunakan } \\
\text { pewarna buatan ( } \text { Rhodamin } B \text { ) }\end{array}$ & 17 & 54,83 & 10 & 32,25 & 4 & 12,9 \\
\hline 7 & Saus yang banyak diminati konsumen & 9 & 29,03 & 10 & 32,25 & 12 & 38,7 \\
\hline 8 & $\begin{array}{l}\text { Ciri fisik saus yang mengandung } \\
\text { pewarna buatan yang dilarang }\end{array}$ & 0 & 0 & 19 & 61,29 & 12 & 38,7 \\
\hline 9 & $\begin{array}{l}\text { Bahaya pemakaian pewarna sintetik } \\
\text { (Rhodamin B) pada makanan }\end{array}$ & 12 & 38,7 & 10 & 32,25 & 9 & 29,03 \\
\hline 10 & Berapa jenis pewarna makanan & 20 & 64,51 & 11 & 35,48 & 10 & 32,25 \\
\hline
\end{tabular}

Sumber : Data Primer 2015 
Berdasarkan tabel diatas bahwa hasil penilaian tingkat pengetahuan pedagang melaui lembar pertanyaan terhadap pedagang dengan mengajukan 10 pertanyaan seperti yang tercantum pada tabel dilakukan penilaian berdasarkan nilai yang diperoleh, sehingga diperoleh hasil tingkat pengetahuan "Cukup" sebanyak 28 pedagang $(90,32 \%)$ dan 3 pedagang $(9,67 \%)$ memiliki tingkat pengetahuan "Kurang", dan terdapat 5 dari 28 pedagang berpngetahuan cukup masih menggunakan saus yang mengandung Rhodamin $B$.

\section{KESIMPULAN DAN SARAN}

\section{Kesimpulan}

1. Pemeriksaan secara fisik kandungan Rhodamin $B$ pada 3 merk saus jajanan yang digunakan 31 pedagang, hanya ada 1 saus yang digunakan oleh 8 pedagang menunjukkan ciri-ciri mengandung Rhodamin $B$, yaitu warna cerah mengkilap dan lebih mencolok, serta baunya tidak alami sesuai makanannya. Dan 2 merk saus lain yang digunakan oleh 23 pedagang tidak menunjukkan ciri-ciri fisik saus yang mengandung Rhodamin B.

2. Pemeriksaan laboratorium terhadap 3 merk saus yang digunakan oleh 31 pedagang, menunjukkan bahwa hanya 1 merk (yang digunakan oleh 8 pedagang) dinyatakan mengandung Rhodamin $B$.

3. Penilaian tingkat pengetahuan pedagang saus jajanan diperoleh hasil sebanyak 28 pedagang memiliki pengetahuan "Cukup" dan 3 pedagangmemiliki tingkat pengetahuan "Kurang". Dimana 5 dari 28 pedagang yang memiliki pengetahuan cukup menggunakan Rhodamin $B$ pada saus jajanan yang dijualnya.

\section{Saran}

1. Bagi Dinas Pendidikan

Perlu melakukan penyuluhan dan memberikan informasi kepada guru dan anak-anak didiknya tentang bahaya penggunaan BTM yang dilarang pemerintah (Rhodamin B) dan kegunaannya pada makanan terutama pada saus yang dipakai pedagang.

2. Dinas Kesehatan

Perlu melakukan peningkatan pengawasan dan pengendalian secara rutin terhadap pedagang yang menjual saus jajanan di Sekolah Dasar yang menggunakan saus mengandung BTM berbahaya seperti Rhodamin $B$.

3. Bagi Pedagang

Lebih hati-hati dalam memilih saus untuk di gunakan pada jajanan anak sekolah dasar, agar makanan lebih aman dan tidak membahayakan konsumen terutama anak-anak usia sekolah dasar. Karena pemberian pewarna berbahaya seperti Rhodamin $B$ telah dilarang sesuai dengan Permenkes No : 239/MENKES/PER/V/85 Tentang Zat Warna Tertentu yang Dinyatakan Berbahaya

4. Bagi Masyarakat

Masyarakat sebagai pembeli harus lebih teliti dalam membeli jajanan yang menggunakan saus, dan harus lebih teliti lagi dalam mengetahui ciri-ciri saus yang mengandung Rhodamin $B$.

\section{DAFTAR PUSTAKA}

Andrawulan, N., Kusnandar, F., dan Herawati, D., 2011. Analisis Pangan. Dian Rakyat, Jakarta.

BPOM- Badan Pengawas Obat dan Makanaan, 2012. Bahaya Rhodamin-B sebagai Pewwarna dalam Pangan.

http://ik.pom.go.id/wpcontent/uploads/2011/11/bahayaRhodamin-B-sebagai-pewarnapada-makanan.pdf (Diakses 7 Maret 2015 10.05)

Dwi Ratna Herniati, 2010. Nikmat Dengan Makanan Sehat dan Bergizi. CV Ricardo. Jakarta.

Eka Reysa, 2013. Rahasia Mengetahui Makanan Berbahaya. Titik Media Publisher. Jakarta

Eriawan, R., Imam, P., 2012. Pangan dan Gizi untuk Kesehatan. Radja Grafindo Persada. Jakarta.

Kementrian Kesehatan RI Politeknik Kesehatan Kemenkes Surabaya. 2014. Pedoman Penulisan Karya Tulis IImiah. Surabaya.

Muchtadi TR, Ayustaning Warno F. 2010. Teknologi Proses Pengolahan Pangan. Alfabeta, Bandung.

Murtiyanti Madya Feni, $d k k, 2013$. Identifikasi Penggunaan Zat Pewarna Pada Pembuatan Kerupuk dan Faktor Perilaku Produsen. ISSN 2252-6781.

Notoatmodjo, Soekidjo, 2010. Metodologi Penelitian Kesehatan. Jakarta, Rineka Cipta.

Notoatmodjo, Soekidjo, 2010. Metodologi Promosi Kesehatan dan IImu Perilaku. Jakarta, Rineka Cipta.

Peraturan Menteri Kesehatan Republik Indonnesia Nomor : 239/MENKES/PER/V/85 Tentang Zat Warna Tertentu yang Dinyatakan sebagai Bahan Berbahaya. 
Peraturan Menteri Kesehatan Republik Indonesia Nomor : 033 Tahun 2012 Tentang Bahan Tambahan Pangan.

Pusat Standarisasi Industri Departemen Perindustrian, 1992. SNI Cara Uji Pewarna Tambahan Makanan 01-2895-1992.

Putra Ilham Rizka $d k k$, 2014. Gambaran Zat Pewarna Merah pada Saus Cabai yang Terdapat pada Jajanan yang Dijual di Sekolah Dasar Negeri Kecamatan Padang Utara.

Rompas, Ivone Cecilia, 2014. Identifikasi Zat Pewarna Rhodamin B Pada Saus Tomat Bakso Tusuk di Sekolah Dasar Kota Manado.

Rosina Emilisa, 2012. Identifikasi Kandungan Formalin dan Tomat Busuk yang Beredar Di Ibu Kota Jakarta.

Rozak, Abdul, 2012. Pengantar Statistika. Malang, Intimedia.

Saparianto, Cahyo, Diana HS, 2010. Bahan Tambahan Pangan. Dalam Dasar-Dasar Kimia Klinis Edisi $K e-4$. Jakarta, Sagug Setyo.
Silviana, Dessy, 2013. Kandungan Rhodamin B pada Krupuk Esek di Industri Rumah Tangga Desa Tlasih Kecamatan Tulangan Kabupaten Sidoarjo Tahun 2013. Kementerian Kesehatan RI Politeknik Kesehatan Kemenkes Surabaya.

Sitanggang Jahyadi, $d k k$. 2013. Analisis Rhodamin $B$ dalam Makanan Jajanan Pasar di Kota Pekanbaru.

Sudarmadji, S., Bambang, H. dan Suhardi. 2010. Analisis Bahan Makanan dan Pertanian, Cetakan 4, Penerbit Liberty. Jogjakarta.

Widoyoko, Putro Eko, 2012. Teknik Penyusunan Instrumen Penelitian. Yogyakarta, Pustaka Pelajar.

Wijaya, D. 2011. Waspadai Zat Aditif Dalam Makananmu. Penerbit Buku Biru, Jogjakarta.

Winarno, F.G, 2010. Kimia Pangan dan Gizi. Jakarta, PT Gramedia Pustaka Utama. 